\title{
Failure Criterion for Adhesively Bonded Joints Using Arcan's Experimental Method
}

\author{
Demetrio Jackson dos Santos \\ Centro de Engenharia, Modelagem e Ciências Sociais Aplicadas, Universidade Federal do ABC - UFABC \\ Gilmar Ferreira Batalha \\ Mechanical Engineering Department, Polytechnic School, University of São Paulo
}

\begin{abstract}
Characterization of polymeric materials mechanical behavior requires some previous knowledge about their structure, which allows the choice of more appropriated models and methods. Polymeric materials, below their glass transition temperature $\left(\mathrm{T}_{\mathrm{g}}\right)$, may be handled as perfect elastic solids, allowing the use of classic mechanics to characterize their behavior. Polymers above their $\mathrm{T}_{\mathrm{g}}$ present a viscous contribution to mechanical behavior, which has to be taken into consideration by modeling it. Adhesively bonded joint, joining of different materials using a polymer as adhesive, adds to the mentioned requirements more parameters, such as surface roughness, adhesive thickness and different types of contributions to adhesively bonded joint strength. This work has the purpose of presenting a mechanical behavior characterization of adhesive bonded joints, concerning their average stress at rupture. A modified Arcan's device was used to obtain the average stress at rupture under different angles or loading conditions, such as pure shear $0^{\circ}$, pure tensile strength $90^{\circ}$ and combined conditions. The experimental results were applied to a theoretical model, which takes into consideration the hydrostatic contribution to the mechanical behavior, called Drucker-Prager Model, which was initially developed to characterize soils.
\end{abstract}

Keywords: Adhesive, Arcan, Drucker-Prager, polymer characterization, failure criterion.

\section{Introduction}

Adhesives usually are polymers, which are applied for joining different materials through the adhesion phenomena established between their surfaces. Both materials are kept together due to different kinds of interactions established between both materials. These interactions may be explained though theoretical models: mechanical, thermodynamic, chemical, inter-diffusion or dipolar approaches ${ }^{[1-4]}$. The use of adhesives at industrial applications have been widely increased during the last years, at non-structural loading condition, such furniture applications ${ }^{[5]}$, at specific and hazardous condition, such as off-shore applications ${ }^{[6]}$ and composites, where the interface between matrix and reinforcement is handled as adhesive interactions ${ }^{[7]}$. Besides the several industrial applications, there is a lack concerning a general model, which should be able to predict or describe the interface or adhesion behavior, due to hard work of separating each interaction type contribution to adhesion strength. At this point it is essential to separate two important, but different, concepts: adhesion strength and joint strength. The adhesion strength is the force developed due to the main type of interactions between adhesive and substrates ${ }^{[3]}$, which were briefly mentioned in this text. To measure properly the adhesion strength, the contribution of each type of interaction should be quantitatively defined and the contribution of elastic behavior of the substrates has to be eliminated from the strength measurement.

Joint strength, or adhesively bonded joint strength, is the force developed by substrates bonded by polymeric materials, against external loading ${ }^{[5]}$. To avoid the influence of undefined adhesion phenomena contribution, the failure of bonded joints are handled as cohesive, it means, the adhesive strength is always higher that the adhesion strength ${ }^{[3]}$. Even handling the adhesion strength apart from joint strength measurements, taken the failure as cohesive, there are some other parameters, which strongly influence the joint behavior: loading type (shear, tensile or combined loadings) ${ }^{[8]}$, adhesive thickness ${ }^{[9]}$ and polymer (adhesive) structure ${ }^{[10,11]}$. Different type of experiments are usually applied to characterize the mechanical behavior of adhesively bonded joints ${ }^{[12,13]}$, such as peeling and lap shear experiments ${ }^{[10]}$ and Arcan tests, which are able to combine shear and tensile stress loading under different angles ${ }^{[14]}$.

This work has the purpose to characterize the mechanical behavior of adhesively bonded joints applying a modified Arcan Device to obtain the strength at rupture, under shear, tensile and combined loadings. The experimental results were applied on the DruckerPrager model, in order to generate a failure criterion (or failure envelope), based on the mean measured stresses. The mentioned failure criterion may be strictly applied to polymers (adhesives) under their glass transition temperature $\left(\mathrm{T}_{\mathrm{g}}\right)$, due to their almost pure elastic behavior ${ }^{[15]}$. Such restriction is based on nonlinear viscoelastic behavior of polymers above their $\mathrm{T}_{\mathrm{g}}$, which is not taken into consideration by the DruckerPrager model ${ }^{[16]}$.

Concerning metals, different failure criterions are available to predict their failure or elastoplastic behavior, such as von Mises criterion. The polymeric structure and behavior make unfeasible the directly application of failure criterion for metals to polymeric materials 
or parts. In general, it is widely accepted that the yield behavior of polymers is dependent on both the deviatoric and hydrostatic stress components while the dependence of hydrostatic stress on yielding for metals is significantly less pronounced ${ }^{[16]}$. Based on hydrostatic component of polymer behavior, there is a need of applying a modified failure criterion, which takes it into consideration without neglect the deviatoric stress, broached by von Mises on the failure criterion for metals, conditions which are considered by the Drucker-Prager criterion ${ }^{[15]}$. This model was initially developed to describe geomaterials and soils behaviors, which are typically described using the theory of elastoplasticity. Since these materials exhibit pressuresensitive behavior, it is important to include this feature into the yield function employed in the constitutive equations ${ }^{[16]}$. Summarizing all these requirements, a failure mean stress criterion was developed (DruckerPrager or modified von Mises), which can be applied to polymeric materials, as follows.

$$
\left(\frac{\lambda-1}{2 \cdot \lambda}\right) \cdot I_{1}+\sqrt{\frac{3}{\lambda} \cdot J_{2}+\left(\frac{\lambda-1}{2 \cdot \lambda}\right)^{2} \cdot I_{1}^{2}}-\sigma_{F}=0
$$

Where $I_{1}$ is the first invariant of stress tensor and $J_{2}$ is the second invariant of stress deviator.

$$
\begin{aligned}
& J_{2}=\frac{\left(\sigma_{x}-\sigma_{y}\right)^{2}+\left(\sigma_{y}-\sigma_{z}\right)^{2}+\left(\sigma_{z}-\sigma_{x}\right)^{2}+6\left(\tau_{x y}^{2}+\tau_{y z}^{2}+\tau_{z x}^{2}\right)}{6} \\
& I_{1}=\sigma_{x}+\sigma_{y}+\sigma_{z}
\end{aligned}
$$

The parameter $\lambda$ is related to the material sensitivity to hydrostatic stress and can be defined by:

$$
\begin{aligned}
& \lambda=\left(\frac{1}{6}\right) \cdot\left(\beta^{2}+\beta \cdot \sqrt{\beta^{2}+12}+6\right) \\
& \beta=3 \cdot \frac{1-v}{1+v} \cdot \frac{\tau_{m s d}}{\sigma_{m s d}}-\frac{(1-2 \cdot v)^{2}}{(1-v) \cdot(1+v)} \cdot \frac{\sigma_{m s d}}{\tau_{m s d}}
\end{aligned}
$$

Where, $(v)$ is the Poisson coefficient for polymer or adhesive.

Using the presented criterion, the material yield stress under uniaxial tension $\left(\sigma_{\mathrm{F}}\right)$ can be calculated, through two experimental data: measured failure tensile stress $\left(\sigma_{\text {msd }}\right)$ obtained from tensile experiment and measured failure shear stress $\left(\tau_{\text {msd }}\right)$ obtained from shear testing ${ }^{[16]}$.

$$
\sigma_{F}=\left[\begin{array}{l}
\frac{\lambda-1}{2 \cdot \lambda} \cdot \frac{1+v}{1-v}+\sqrt{\frac{1}{\lambda \cdot\left(\frac{1-2 \cdot v}{1-v}\right)^{2}+}} \\
\left(\frac{\lambda-1}{2 \cdot \lambda}\right)^{2} \cdot\left(\frac{1+v}{1-v}\right)^{2}
\end{array} \cdot \sigma_{m s d}\right.
$$

All needed data are available to generate a final notation of the failure criterion applicable to adhesive joints. When $\sigma_{\mathrm{F}} \leq \sigma_{\text {theo }}$ and $v$ tends to 0.5 , the DruckerPrager Model can be presented in the following simpler form:

$$
\left(\frac{\tau_{\text {theo }}}{\sigma_{F}}\right)^{2}+k \cdot \frac{\sigma_{\text {theo }}}{\sigma_{F}}=1
$$

Where, $\tau_{\text {theo }}$ and $\tau_{\text {theo }}$ are the theoretical normal or tensile stress at rupture and the theoretical shear stress at rupture, respectively.

$$
k=\left(\frac{\lambda-1}{\lambda}\right) \cdot\left(\frac{1+v}{1-v}\right)
$$

\section{Experimental}

Many Arcan's specimen geometries were proposed for polymer and composite testing ${ }^{[17,18]}$ and few for adhesively bonded joint testing ${ }^{[19]}$, the absence of an international standard concerning this type of specimens generates some limitations, besides the published work describing some geometric parameter influence on experimental results. In this work the Arcan's specimens were obtained by bonding two trapezoidal bodies, through the contact of their superior surface, as shown in the Figure 1.

A structural acrylic adhesive, based on polyurethane ester dimethyl acrylate (Poisson coefficient of 0.4 and $\mathrm{T}_{\mathrm{g}}$ of $63^{\circ} \mathrm{C}$ ), was used to bond the specimen surfaces. 2-ethylhexanoic acid was sprayed on both surfaces as cure initiator, before to apply the adhesive. The adhesive thickness was controlled by glass balls with diameter of $0,1 \mathrm{~mm}$, the bonded surface has the following dimensions: $16 \mathrm{~mm}$ (width) $\times 30 \mathrm{~mm}$ (depth). The Arcan's specimens were manufactured from SAE 1010 steel, with elastic modulus (E) of $207 \mathrm{GPa}$ and a Poisson coefficient (v) of 0,28 , three specimens of each condition were tested under the following angles: $0^{\circ}$ (pure shear), $22.5^{\circ}, 45^{\circ}, 67.5^{\circ} \mathrm{e}$ $90^{\circ}$ (pure tensile), as shown in the Figure 2.

The tests were carried out using an EMIC DL5000 equipment with load cell up to $50 \mathrm{kN}$, under displacement rates of $2 \mathrm{~mm} / \mathrm{min}$ and $10 \mathrm{~mm} / \mathrm{min}$. The experimental results were applied to Drucker-Prager Model in order to generate a failure criterion. The Poisson coefficient, mean "measured failure tensile stress $\left(\sigma_{\text {msd }}\right)$ " and mean "measured failure shear stress $\left(\tau_{\text {msd }}\right)$ " were applied to Equation 5, which allowed calculating the parameters $\beta$ and $\lambda$. Subsequently, the material yield stress under uniaxial tension $\left(\sigma_{\mathrm{F}}\right)$ could be defined (Equation 6), which finally allowed providing the theoretical failure criterion by using the Equation 7 .

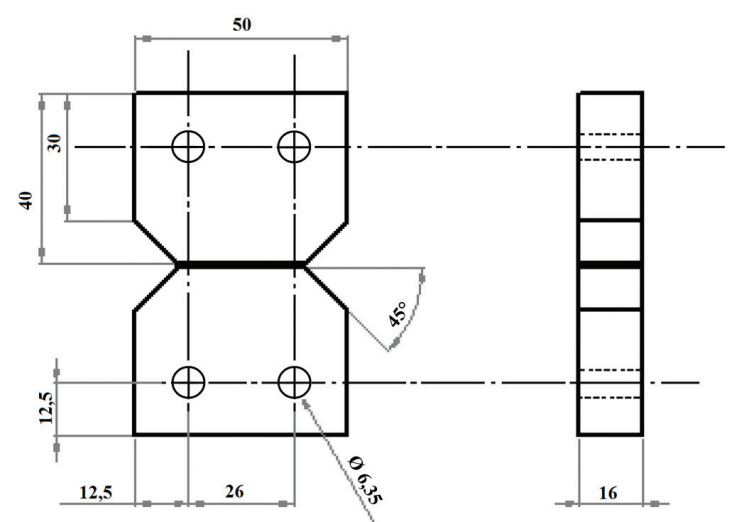

Figure 1. Arcan's specimen geometry. 
A comparison between theoretical failures criterion and experimental results is presented. The results obtained under different angles $(\theta)$ were multiplied by the $\cos (\theta)$ and $\sin (\theta)$ in order to define the shear and tensile stress contribution to the material failure at each tested angle.

\section{Results and Discussion}

Polymeric materials fracture characterization, including adhesives, cannot be accurately carried out through simple single lap shear experiments. Combined loading experiments, such the experiments provided by Arcan's device, may generate multidirectional data, which can accurately support the adhesive behavior characterization. Table 1 shows the mean of average stress at rupture, according to the angle loading for both displacement rates.

As expected the average stress at rupture was increased by varying the specimen's angle from shear to tensile conditions. Concerning the $22.5^{\circ}$ and $67.5^{\circ}$ combined conditions, the higher the tensile contribution to the loading condition, the higher the average stress at break results became. Specifically for the $45^{\circ}$ condition, at displacement rates of $10 \mathrm{~mm} / \mathrm{min}$, some discrepancies have been found between experimental and theoretical data, as shown in the Table 1 and Figure 3.

Results obtained from simple lap shear experiments cannot be directly compared to the $0^{\circ}$ results in this work, due to different bonded geometry surface and substrate stiffness. The Arcan's specimens, used in this work, may be treated as bodies with extreme high stiffness. In short, the experimental data by itself have provided an initial mechanical characterization, by providing the strength at rupture under many loading conditions. A step forward might be the application of the experimental results

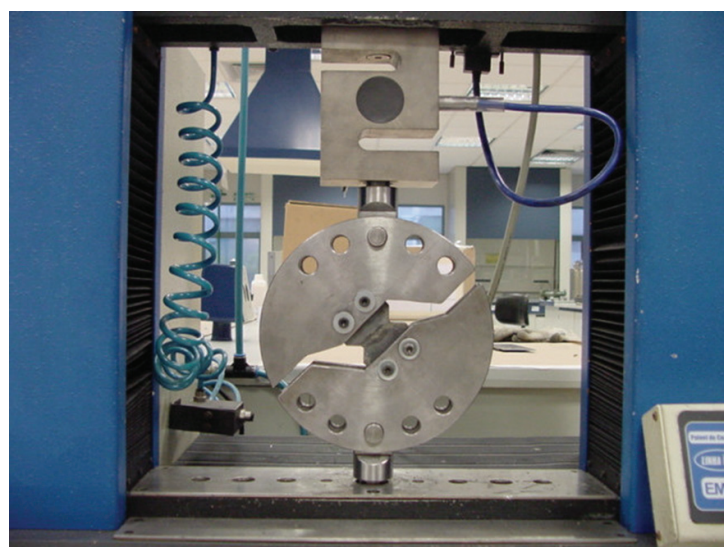

Figure 2. Arcan's device and specimen. measurements at $45^{\circ}$. on the Drucker-Prager failure criterion, which model a theoretical failure stress for all possible combination of shear and tensile loadings.

Theoretical curves, concerning average stress criterion, can be generated using simple mean of average tensile stress at rupture results, mean of average shear stress at rupture, or the combination of both loading types ${ }^{[16]}$. Figures 3 and 4 show the theoretical curves generated by the results of shear and tensile stress at rupture, which were applied to Drucker-Prager criterion. Figure 5 shows that no relevant difference was verified on the average stress at rupture by changing the displacement rate from $2 \mathrm{~mm} / \mathrm{min}$ to $10 \mathrm{~mm} / \mathrm{min}$.

Experimental data concerning both displacement rates are in agreement with theoretical curves. The larger difference between experimental data and simulation was verified for specimens tested at $45^{\circ}$ and $10 \mathrm{~mm} / \mathrm{min}$ of displacement rate. Adhesively bonded joints present, under loading, stress peaks at their extremities ${ }^{[14,20]}$. Low displacement rates may allow the polymeric structure to rearrange (during test) and to distribute the stress peaks, which creates a more uniform stress distribution and consequently a higher strength at break ${ }^{[20]}$. By increasing the displacement rate the molecular rearrangement is restrict, which may generate higher stress peaks and consequently lower strength at break. Taking into consideration the absence of a displacement rate parameter on the Drucker-Prager Model, the below presented behaviors can be used as hypothesis to explain the increased difference, between experimental $x$ theoretical values, observed at $10 \mathrm{~mm} / \mathrm{min}$.

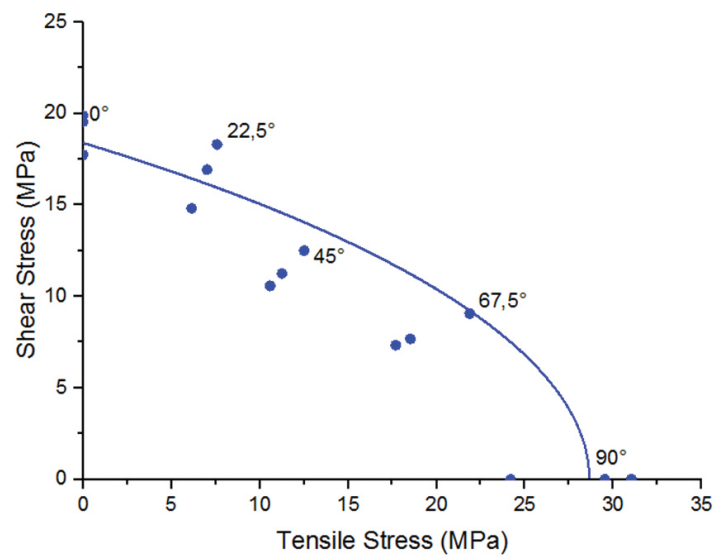

Figure 3. Failure criterion, based on average shear/tensile stresses, for displacement rate of $10 \mathrm{~mm} / \mathrm{min}$ (points - experimental results $x$ blue line - Drucker-Prager Model).

Table 1. Experimental results at $2 \mathrm{~mm} / \mathrm{min}$ and $10 \mathrm{~mm} / \mathrm{min}$ under five angle conditions.

\begin{tabular}{ccccc}
\hline Angle & $\begin{array}{c}\text { mean stress at break } \\
(\mathbf{M P a}) \mathbf{- 2} \mathbf{~ m m} / \mathbf{m i n}\end{array}$ & $\begin{array}{c}\text { standard deviation } \\
(\mathbf{2} \mathbf{~ m m} / \mathbf{m i n})\end{array}$ & $\begin{array}{c}\text { mean stress at break } \\
(\mathbf{M P a}) \mathbf{~ 1 0 ~} \mathbf{~ m} / \mathbf{m i n}\end{array}$ & $\begin{array}{c}\text { standard deviation } \\
(\mathbf{1 0} \mathbf{~ m m} / \mathbf{m i n})\end{array}$ \\
\hline $0^{\circ}$ (shear) & $18.86\left(\tau_{\mathrm{msd}}\right)$ & 1.00 & 19.06 & 1.15 \\
$22.5^{\circ}$ & 18.33 & 1.45 & 17.88 & 1.67 \\
$45^{\circ}$ & 16.09 & 1.86 & 16.20 & 1.38 \\
$67.5^{\circ}$ & 22.48 & 2.06 & 20.96 & 2.40 \\
$90^{\circ}$ (tensile) & $27.42\left(\sigma_{\mathrm{msd}}\right)$ & 2.91 & 28.25 & 3.59 \\
\hline
\end{tabular}




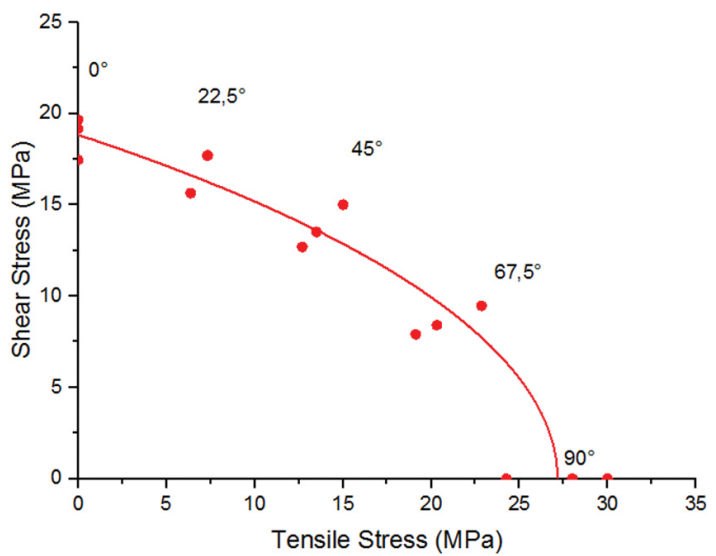

Figure 4. Failure criterion, based on average shear/tensile stresses, for displacement rate of $2 \mathrm{~mm} / \mathrm{min}$ (points - experimental results $\mathrm{x}$ red line - Drucker-Prager Model).

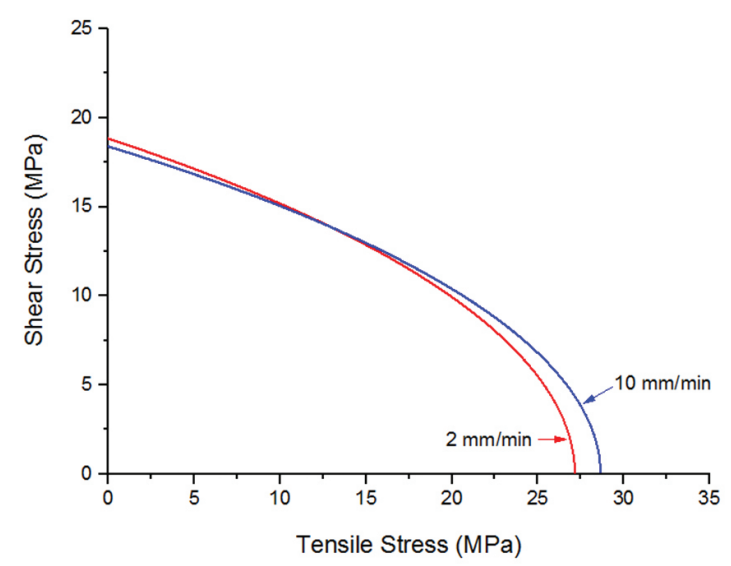

Figure 5. Comparative of theoretical curves between displacement.

Some other factors can influence experimental results concerning adhesively bonded joints. The presence of bubbles in the adhesive, surface irregularities or porosity could act as stress concentrator and lead to creation of a pre-crack. In a 2-D case even a circular hole leads to a magnification of stress by a factor $3^{[8]}$. This can used, in association with rearrangement restriction caused by higher displacement rates, to indicate a failure mechanism in order to explain the results divergence at $45^{\circ}$ and $10 \mathrm{~mm} / \mathrm{min}$.

In adhesively bonded joints with higher stiffness adhered (substrate), like proposed in this work, the joint strength is more dependent on adhesive properties than on adhered properties ${ }^{[21]}$, which emphasizes the possible influence of factors like air bubbles and movement restriction on the observed variation at $45^{\circ}$ and $10 \mathrm{~mm} / \mathrm{min}$.

\section{Conclusions}

The experimental results using Arcan's device and specimens, which were applied to a failure criterion called Drucker-Prager have allowed the following conclusions:
- Modified Arcan specimens can be used to characterize the mechanical behavior of adhesively bonded joints, below glass transition temperature, concerning average stress at rupture under shear, tensile and combined loading conditions;

- Experimental data obtained from Arcan's specimen can be applied to theoretical Drucker-Prager model, in order to provide a theoretical failure criterion based on average stress at rupture;

- The generated theoretical curves are in agreement with experimental data;

- High displacement rates impacts on agreement between experimental results and theoretical values, such behavior has rearrangement restriction as possible cause;

- Adhesive line defects (holes) influences the experimental results.

\section{References}

1. Awajas, F.; Gilbert, M.; Kelly, G.; Fox, B. \& Pigram, P. J. - Prog. Polym. Sci., 34, p.948 (2009).

2. Szymczyk, K.; Zdziennicka, J. \& Janczuk, B. - Colloid. Surface. A, 402, p.139 (2012). http://dx.doi.org/10.1016/j. colsurfa.2012.02.055

3. Kim, W. S.; Yun, I. H.; Lee, J. J. \& Jung, H. T. - Int. J. Adhes. Adhes., 30, p.408 (2010). http://dx.doi.org/10.1016/j. ijadhadh.2010.05.004

4. Marshall, S.J.;Bayne, S.C.; Baier, R.; Tomsia,A.P.\& Marshall, G. W. - Dent. Mater., 26, p.e11, (2010). PMid:20018362. http://dx.doi.org/10.1016/j.dental.2009.11.157

5. Pinto, M. E. C. B.; Visconte, L. L. Y.; Nunes, R. C. R. \& Luz, R. F. - Polímeros, 21, p.265 (2011). http://dx.doi. org/10.1590/S0104-14282011005000047

6. Pessanha, M. C. R.; Dias, D. P.; Filgueira, M.; Paranhos, R. P. R. \& Farias, O. L. - Polímeros, 18, p.70 (2008).

7. Pires, E. N.; Merlini, C.; Al-Qureshi, A.; Salmoria, G. V. \& Barra, G. M. O. - Polímeros, 22, p.339 (2012). http:// dx.doi.org/10.1590/S0104-14282012005000053

8. Bresson, G.; Jumel, J.; Shanahan, M. E. R. \& Serin, P. - Int. J. Adhes. Adhes., 35, p.27 (2012). http://dx.doi. org/10.1016/j.ijadhadh.2011.12.006

9. Davies, P.; Sohier, L.; Cognard, J. Y.; Bourmaud, A.; Choqueuse, D.; Rinnert, E. \& Créac'hcadec, R. - Int. J. Adhes. Adhes., 29, p.724 (2009). http://dx.doi.org/10.1016/j. ijadhadh.2009.03.002

10. Garcia, F. G.; Sampaio, E. M.; Neves, A. F. \& Oliveira, M. G. - Polímeros, 18, p.30 (2008).

11. Garcia, F. G.; Leyva, M. E. \& Queiroz, A. A. A. - Polímeros, 20, p.148 (2010). http://dx.doi.org/10.1590/ S0104-14282010005000021

12. Dos Santos, D. J.; Tavares, L. B. \& Batalha, G. F. - JAMME, 38, p.33 (2010).

13. Dos Santos, D. J.; Tavares, L. B. \& Batalha, G. F - JAMME, 46, p.33 (2011).

14. Cognard, J. Y.; Créac'hcadec, R.; Sohier, L. \& Davies, P. - Int. J. Adhes. Adhes., 28, p.393 (2008). http://dx.doi. org/10.1016/j.ijadhadh.2008.04.006

15. Luo, Y. \& Kang, Z. - Comput. Struct., 90-91, p.65 (2012). http://dx.doi.org/10.1016/j.compstruc.2011.10.008 
16. Kreuzer, R. \& Romanos, G. - "Formed-in-place gaskets in powertrain applications: experimental and numerical evaluation under service conditions", SAE International (2006). (SAE Technical Paper 06FFL-172). http://dx.doi. org/10.4271/2006-01-3353

17. Pucillo, G. P.; Grasso, M; Penta, F. \& Pinto, P. - Eng. Fract. Mech., 78, p.1729 (2011). http://dx.doi.org/10.1016/j. engfracmech.2011.02.002

18. Gning, P. B.; Delsart, D.; Mortier, J. M. \& Coutellier, D. - Compos. Part B-Eng., 41, p.308 (2010). http://dx.doi. org/10.1016/j.compositesb.2010.03.004
19. Cognard, J. Y.; Davies, P.; Sohier, L. \& Créac'hcadec, R. Compos. Struct., 76, p.34 (2006). http://dx.doi. org/10.1016/j.compstruct.2006.06.006

20. Hu, J. K.; Schmit, F.; Baptiste, D. \& François, D. J. Appl. Mech., 63, p.21 (1996). http://dx.doi.org/10.1115/1.2787202

21. Clarke, M. I.; Broughton, J. G.; Hutchinson, A. R. \& Buckley, M. - Int. J. Adhes. Adhes., 44, p.226 (2013). http:// dx.doi.org/10.1016/j.ijadhadh.2013.03.003

Received: July 6, 2013 Revised: Jan. 20, 2014 Accepted: Apr. 16, 2014 